\title{
Epothilone D
}

National Cancer Institute

\section{Source}

National Cancer Institute. Epothilone D. NCI Thesaurus. Code C2672.

A natural polyketide compound isolated from the myxobacterium Sorangium cellulosum.

Also known as desoxyepothilone $B$, epothilone $\mathrm{D}$ binds to tubulin and inhibits the disassembly of microtubules, resulting in the inhibition of mitosis, cellular proliferation, and cell motility. ( $\mathrm{NCIO4)}$ 